\title{
Towards a Thorough Framework in Strategic Reading Comprehension Instruction
}

\author{
Asma Dabiri ${ }^{1}$; Sara Kashefian-Naeeini ${ }^{2 *}$ \\ 1\&2* Department of English Language, School of Paramedical Sciences, Shiraz University of Medical Sciences, \\ Shiraz, Iran \\ ${ }^{2 *}$ Philosophy of Life and Healthy Lifestyle Research Center, Shiraz University of Medical Sciences, Shiraz, Iran \\ *Correspondence Emails: kashefian@gmail.com ; kashefian@sums.ac.ir
}

http://dx.doi.org/10.18415/ijmmu.v8i12.3268

\begin{abstract}
Reading comprehension skill is widely used in EFL settings. English language learners, especially, in academic settings, are provided with a high level of literacy and comprehension of texts, where they are provided with a considerable portion of knowledge fused into written documents. Therefore, the skill of processing texts efficiently with sufficient comprehension gains significance in students' academic accomplishments. Nevertheless, the concept of reading as a general term and strategic reading as an enabling skill should be differentiated in reading comprehension instruction. Providing students with written texts without Empowering them to deal with the texts cannot yield fruitful results in designated goals of reading comprehension. In view of that, the present research tried to introduce strategic reading as a holistic concept and endeavored to enlighten each aspect of it using reading models and frameworks presented in the related literature on reading comprehension. Instructors, with the awareness of strategic reading as an important reading skill, can determinedly instruct and implement it in their classrooms to enable students resourcefully for their educational goals which eventually leads to academic and professional achievements.
\end{abstract}

Keywords: Reading Comprehension; Reading Models and Frameworks; Strategic Reading Comprehension

\section{Introduction}

In EFL settings, although, teaching reading strategies in reading comprehension courses is highly acknowledged, and instructors are recommended to practice reading strategies, what can be really experienced is just merely exposing students with written documents without enabling them to be strategic readers. Accordingly, the ultimate outcome in reading comprehension courses is sometimes not attained. Teachers, as it is supposed to be common practice, should guide learners to the implementation of strategic reading. It is noteworthy to mention that teaching some reading passages accompanied by a number of vocabulary items and structures without practicing strategic reading comprehension does not lead to the ultimate goal of training strategic readers that they can read efficiently texts and passages beyond the scope of the textbooks. Therefore, first of all, teachers themselves should have a clear understanding of the strategic reading comprehension and be aware of each of its facets Then, they must be aware of the effective strategies which can be employed to address the drawback, that is, the lack of strategic reading comprehension in reading comprehension courses. 
There are a large number of studies in the area of reading comprehension both in the first and second or foreign language. However, to a great extent, to understand the nature of the reading comprehension processes, lower-level cognitive processes such as word recognition, lexical access, syntactic parsing and sentence comprehension have been explored in the related literature (Carver, 1997, 1998; Just \& Carpenter, 1992; Perfetti, 1991; Rayner \& Pollatsek, 1989; Rumelhart \& McClelland, 1986). The studies done from this perspective, in line with the cognitive psychology, primarily attempted to give a detailed account of lower-level cognitive processing such as word recognition and syntactic parsing for the efficiency of reading and envisaged reading as a process of meaning making within the boundaries of a sentence. In these studies, the sentence was considered to be the unit of comprehension, and comprehension of a text entailed comprehension of sentences.

Following studies on lower-level cognitive processes, there were studies which dealt with reading comprehension processes beyond the sentence level, Kintsch and van Dijk (1983) and van Dijk and Kintsch (1983) investigated reading comprehension processes at the level of a text. Researchers in the field of discourse studies investigated reading comprehension processes at the level of text, too. For example, in studies by Gernsbacher (1990), Goldman and Rakestraw (2000) and Meyer (1999), the goal of comprehension was building cohesive mental representations or structures of a text. Studies which dealt with reading comprehension processes at the level of a text reached the conclusion that the information in a text is condensed to a base form in accordance with the reader's current goals. The readers resort to their background knowledge of several types, lexical, and syntactic knowledge as well as prior information at higher levels of content and text structure at the level of textual reading comprehension. Discourse models of reading attempted to explain comprehension beyond a sentence by focusing on the text characteristics such as genre-related features, development of discourse, organization of information, establishment of coherence throughout a text and lexical choices in specific genres.

In educational settings, in addition to reading comprehension at the textual level, reading and obtaining information from multiple sources is an essential skill too. Studies by Dabiri, Rashidi, Saadat, Sahragard and Alimorad (2016), and Khalifa and Weir (2009) illustrated that careful reading at the levels of a sentence and a text alone are inadequate for undergraduates to accomplish academic reading tasks at the university level. Careful reading at the level of multiple texts is also important and required of undergraduates to accomplish academic reading purposes. As it is marked in studies done by Bensaad and Ghania (2020), Hawkey (2006), Krishnan (2011), and Weir, Green, Hawkey, Devi, and Unaldi (2009), in higher education, reading comprehension is not limited to reading at the lower levels. Reading multiple texts is also an indispensable expertise in academic programs as the provided set of courses entails reading across texts to accomplish the desired academic goals and to gain an accumulated and deep understanding leading to long-term learning. Moreover, it can be figured out that reading is as an umbrella term comprising cognitive processing at different levels: the propositional, situational and document models. Consequently, a model/framework of reading is needed to combine the types of reading that have been discussed above; namely, reading comprehension at sentence, text and intertextual levels. More importantly, for testing purposes, the underlying cognitive processes as well as contextual features that might form the reading processes such as textual and inter-textual features were to be identified.

\section{Reading Types in Models /Frameworks}

Among earlier studies, Weir's (1993) study is one of the influential studies that investigated reading activities in university programs where several careful reading types as well as expeditious reading types were identified as important for both undergraduate and post graduate students. Later on, Urquhart and Weir (1998) provided a refined form of Weir's (1983) reading framework. They proposed reading types that were shaped by the purposes and processes of reading summarizing both local versus global and expeditious versus careful types of reading skills that defined successful academic reading. In their framework, careful reading at the local level comprised understanding the syntactic structure of a 
sentence and a clause including lexical and/or grammatical cohesion and understanding lexis-i.e., deducing meaning of lexical items from morphology and context. Careful reading at the global level, on the other hand, involved reading carefully to establish accurate comprehension of the explicitly stated main ideas the author wished to convey and the propositional inferences. (See Table 2.1 for types of reading by Urquhart and Weir, 1998).

Table 1. Types of reading (Urquhart and Weir, 1998)

\begin{tabular}{|c|c|c|}
\hline & Global level & Local level \\
\hline $\begin{array}{l}\text { Careful } \\
\text { reading }\end{array}$ & $\begin{array}{c}\text { - Establishing accurate comprehension of } \\
\text { explicitly stated main ideas and supporting } \\
\text { details across sentences } \\
\text { - Making propositional inferences } \\
\text { - Establishing how ideas and details relate to } \\
\text { each other in a whole text } \\
\text { - Establishing how ideas and details relate to } \\
\text { each other across texts }\end{array}$ & $\begin{array}{l}\text { •Establishing accurate } \\
\text { comprehension of explicitly } \\
\text { stated main idea or supporting } \\
\text { details within a sentence } \\
\text { • Identifying lexis } \\
\text { •Understanding syntax }\end{array}$ \\
\hline $\begin{array}{l}\text { Expeditious } \\
\text { reading }\end{array}$ & $\begin{array}{c}\text { - Skimming quickly to establish: } \\
\text { discourse topic and main ideas, or structure of } \\
\text { text, or relevance to needs } \\
\text { - Search reading to locate quickly and } \\
\text { understand information relevant to } \\
\text { predetermined needs }\end{array}$ & $\begin{array}{l}\text { - Scanning to locate specific } \\
\text { points of information }\end{array}$ \\
\hline
\end{tabular}

Enright, Grabe, Koda, Mosenthal, Mulcahy-Ernt and Schedl (2000) offered a framework of reading which summarized reading at four levels briefly described below and the levels of reading were formulated from the reader's purpose perspective as the guiding principle for the testing designs. The four levels were:

1. Searching for specific information and comprehending discreet pieces of information require rapid and automatic identification of words, working memory efficiency, and fluency in reading.

2. Reading for basic comprehension requires understanding the general topic or main idea, important facts and details by forming understanding of the main theme of the text without necessarily having to form an integrated understanding of the text. Reading for basic comprehension involves understanding a subset of individual ideas, the ability to construct a text model representation of what is read and also the ability to form a relevant situation model.

3. Reading to learn involves understanding detailed information and connecting them into a coherent whole by understanding cause-and-effect relationships, comparisons and contrasts, classification relationships, and persuasive intent. Reading to learn requires a more elaborated model of the text construction, organizing conceptual information, and suggests an efficient alignment of the text and the situation model.

4. Reading to integrate information across multiple texts incorporates working across two or more texts and generating an organizing frame that is not explicitly stated. For this type of reading, an intertext model of comprehension through generating a conceptual frame is required.

One of the influential studies in the area of careful reading comprehension research was the study done by Khalifa and Weir (2009). In their study which assessed second language reading, they proposed an influential reading framework which was an extension of Urquhart and Weir's (1998) reading framework. (See Figure 2.2 for Khalifa and Weir's (2009) reading framework). What they added were the cognitive, linguistic and contextual aspects of reading into a more unified framework of reading 
assessment. In their framework, the place and role of linguistic elements at different textual levels (global versus local) along with different reading skills and strategies (expeditious versus careful) were investigated and explicit references to contextual variables were made. The framework accounted for such important variables as the reader's purpose, comprehension focus, text coverage, rates of reading and relationship with the underlying processes. It combined premises of Kintsch and van Dijk (1983) and Just and Carpenter (1992) to adequately account for the reading behavior both at the local and global levels using expeditious and careful reading processes.

In Khalifa and Weir's (2009) reading framework, reading was conceptualized as having several types: expeditious versus careful and local versus global reading. Moreover, careful reading was further divided into four levels including within sentence (propositional meaning), across sentences (mental model, ongoing meaning making as the reader proceeds the text), text (text model) and texts (documents model). The framework accommodated the cognitive processing required for different levels of reading starting from the word level and extending to the multiple text level. In their model, contextual parameters-i.e., text and task features, performance conditions that affect reading comprehension and thus test performance-were explicitly accounted for. They hypothesized that difficulty in reading is a function of the level of processing required by the reading purpose and the complexity of the text(s). Moreover, in the framework, the monitor component is responsible for checking accuracy and appropriateness of comprehension and the reader's reading purposes by making shifts in reading types when necessary. The knowledge base represents several different types of background information that readers might need to incorporate in the reading process for successful comprehension. The components of the knowledge base explain the elements required for comprehension. Through inference, the reader relates the message to the context.

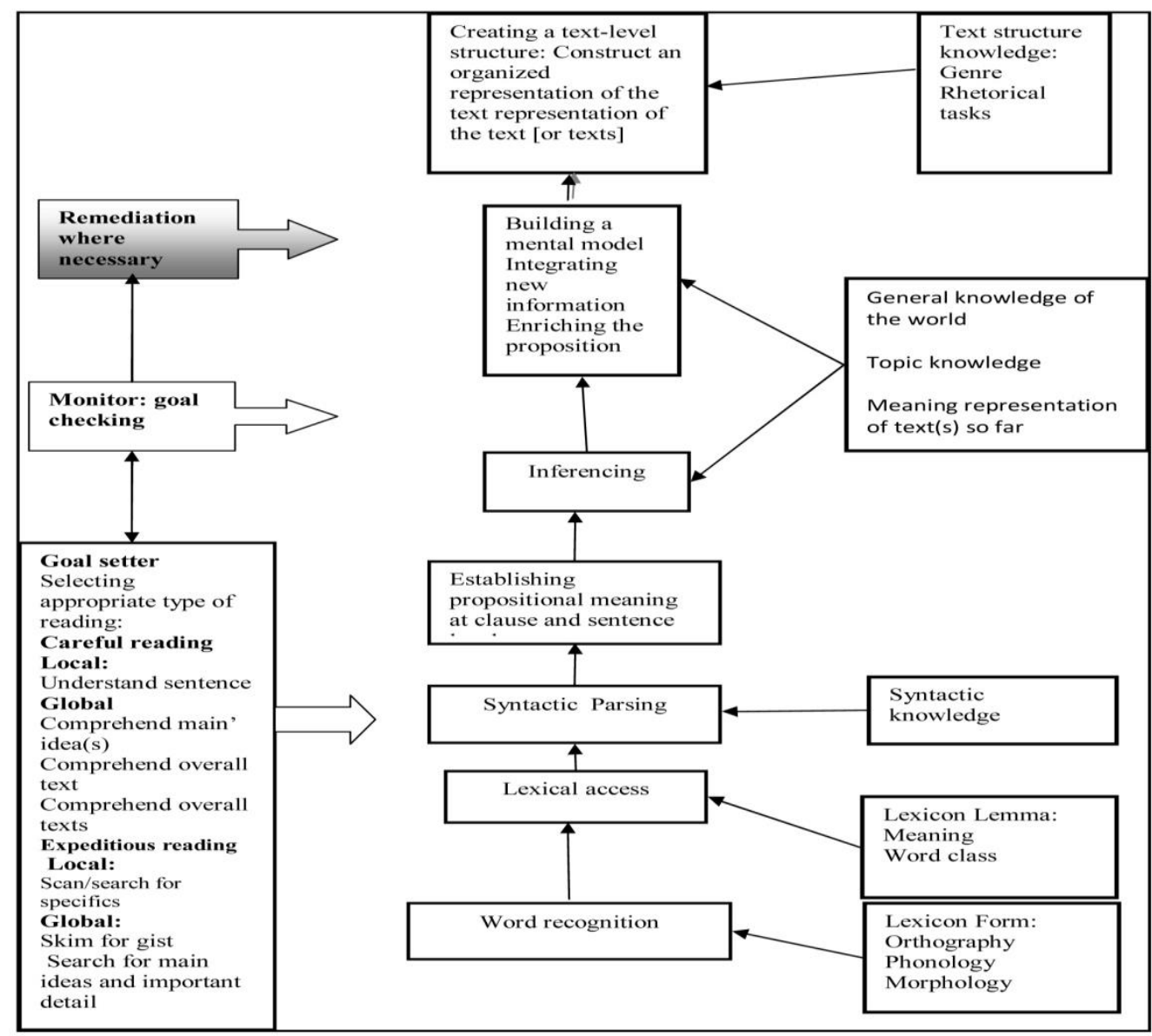

Figure 1. Khalifa and Weir's (2009) reading framework 
In addition, inferencing is also functional in establishing coherence and meaning between propositions as the reader integrates new information into a mental representation of the text. This is the stage where the reader starts to identify main ideas and impose a hierarchical structure on the information in the text. It is the stage where microstructure rules are at work to link the textual pieces and reduce the content to higher propositions to be stored in the working background knowledge on the content of the text. Moreover, the meaning formed on the text so far facilitates inferencing and control of coherence and consistency in the text. In the framework, the goal setter element accounts for the meta-cognitive activities in deciding the level of processing when the text will be approached by the reader.

From among the models of reading comprehension at different levels and types, Urquhart and Weir's (1998) reading model dealt with reading comprehension at the careful and expeditious types and divided them into the local and global levels. Enright et al. (2000) added the level of processing multiple texts to the model. In this model, reading for basic comprehension is basically reading at the sentence or paragraph level (across sentences). Reading to learn is at the text level. The fourth level, as the name suggests, involves the processing of several texts and determines the relations of information between texts and integrates them. What Khalifa and Weir (2009) put forward were careful reading processes at the local and global levels. Careful reading at inter-textual level had also been acknowledged as an additional level of processing, but it was not dealt with in detail. As a result, their reading framework accounted for the reader's purpose in the selection of the type of reading to be engaged, and the knowledge base the reader brings to the reading process for the smooth comprehension.

In these models, reading comprehension has been divided into careful and expeditious reading types and further they organized each type into local and global levels. Nevertheless, reading at the levels of sentence and text was the main focus of the studies done so far while inter-textual level of reading was not thoroughly accounted for. So, empirical studies are needed to investigate this issue in more detail to represent this level of reading in its all possible aspects and to establish the theoretical basis for what goes on when readers read at higher levels of text or multiple text in order to investigate the different cognitive and contextual features that define the types of reading above the sentence level. In general, empirical research results revealed that reading comprehension at the text and inter-text levels does not develop once word decoding and meaning association are acquired, but that it is dependent on different skills. In a study conducted by Dabiri et al. (2016), in an attempt to evaluate Khalifa and Weir's (2009) reading framework in terms of reading processes, textual and inter-textual reading of a group of Iranian EFL undergraduates' careful English reading types were investigated. In that research, Khalifa and Weir's (2009) reading framework was used to propose a more inclusive aspect of a careful reading framework and the reading construct for instructional and assessment goals. In the proposed careful reading framework that was suggested in their study, some new variables such as educational level, age, documents knowledge, better understanding and careful reading at multiple text level structures were added to Khalifa and Weir's (2009) reading framework. (See Figure 2 for Dabiri et al.'s (2016) proposed reading framework). 


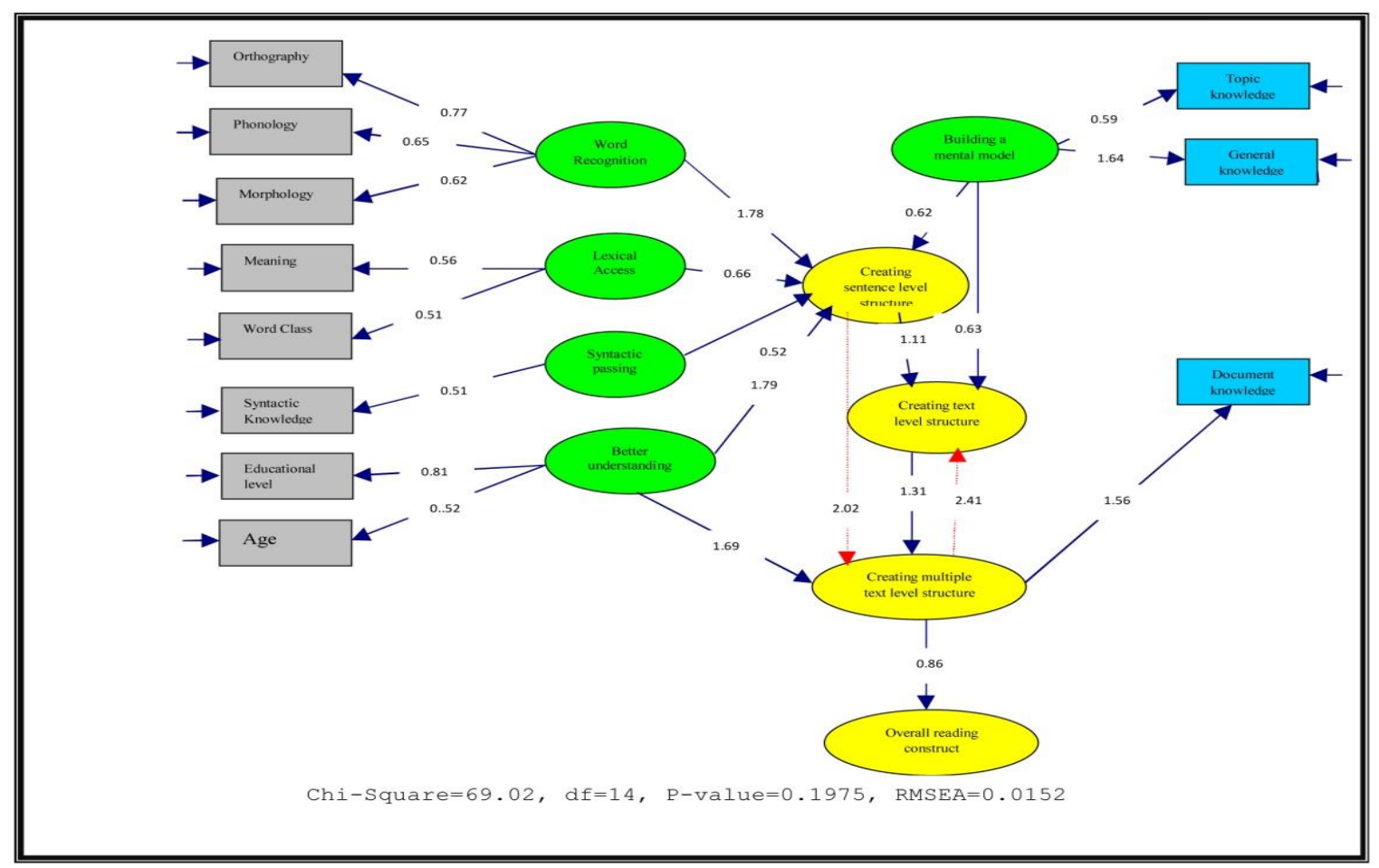

Figure 2. The proposed careful reading framework

\section{Toward a Strategic Reading Comprehension Framework}

According to the studies done on different aspects of reading and the proposed reading models and frameworks in the aforementioned related literature, instructors should focus on strategic reading comprehension in reading comprehension courses. Subsequently, the following model can be implemented as a guideline based on the studies done on this area. (See Figure 3 for proposed instructional reading framework).

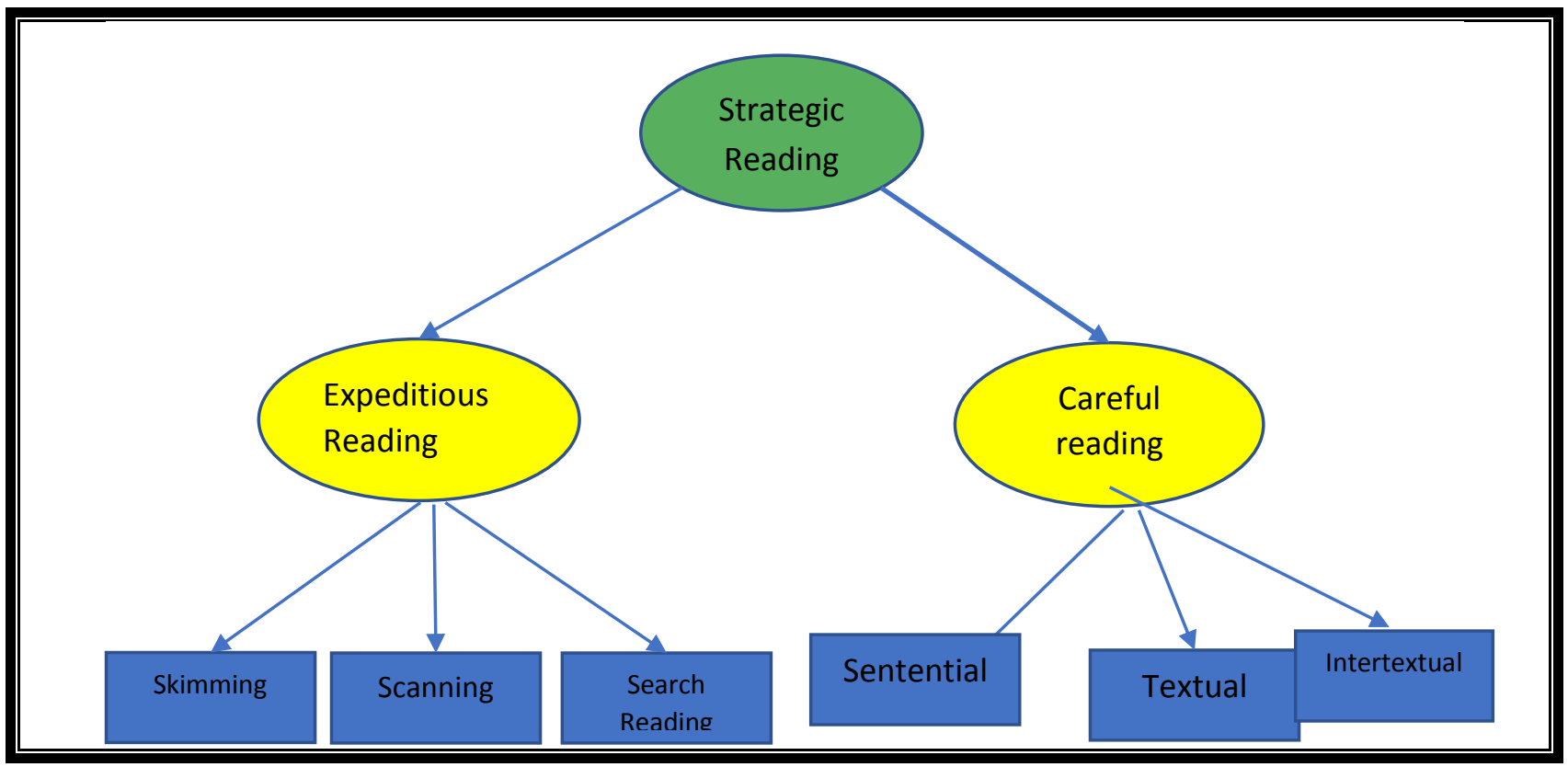

Figure 3. The proposed instructional careful reading framework 
Subsequently, it is illuminating for instructional purposes, to define each facet of the model to have a clear understanding of what strategies are involved in strategic reading comprehension.

Skills and strategies: Carrell (1989) suggested that inefficient use of reading strategies, besides other factors like lack of proficiency in the target language and vocabulary, can have an impact on learners' target language proficiency. The right combination of skills or strategies employed is essential to enhance readers' effective comprehension. In this model, reading is viewed as a cognitive process in which readers employ different skills and strategies or combinations of the two in achieving sentence, text and inter-textual careful and expeditious reading comprehension. It should be stated that in the literature, the terms skills and strategies are used interchangeably to describe the reading activity. In this model, the terms skills and strategies are also used in the same way to describe the careful reading types. However, in order to particularly define them, Cohen (1998) and Urquhart and Weir (1998) defined strategies as conscious problem-solving activities while skills referred to abilities that are performed mostly in a subconscious manner.

Reading comprehension: Rosenfeld, Oltman and Sheppard (2004) defined reading as dealing with language messages in written or printed form. In a similar vein, reading has been defined as the process of receiving and interpreting information encoded in language via media such as print and others by using different processes with various purposes (Grabe \& Stroller, 2002). In terms of a cognitive process, Stanovich (2000) viewed reading as a cognitive activity that largely takes place in the mind, whose physical manifestations such as eye movements, and subvocalization are comparatively apparent.

Careful reading and expeditious reading: The nature of the reading skill has frequently been defined through taxonomies which divide the reading construct into skills and sub-skills as they relate to reading purposes and processes (e.g., Carver, 1997; Grabe \& Stoller, 2002; Munby, 1978; Urquhart \& Weir, 1998). The existence of a variety of approaches to the explanation of the reading construct is itself suggestive of the possibility that reading at different levels may involve different cognitive processes. Therefore, it is important to look at some of the widely accepted definitions explaining reading comprehension processes and different levels of the reading construct. There are usually differences between the types of reading that require quick and strategic reading for the purpose of searching for information as opposed to slower, more detailed reading that involves incremental processing of a text for the purpose of learning from the text. Urquhart and Weir (1998) referred to the former as expeditious reading, and the latter, as careful reading. In reading studies and discussions, careful reading is usually preferred to the other types (e.g., skimming or search reading) by most of the educationalists and psychologists because of its main role in learning. It involves reading to extract full meaning from the material (Weir \& Khalifa, 2008) and is closely related to reading to learn (Weir, Huizhong, \& Yan, 2002). Hence, in reading textbooks, we use more of it (Urquhart \& Weir, 1998).

1. Expeditious reading: According to Weir and Khalifa (2008), unlike careful reading whereby the reader intends to draw full meaning from the material, expeditious reading involves "quick, selective and efficient reading to access desired information in a text" (p. 5). In expeditious reading, the linearity of a text is not necessarily followed as the reader attempts to sample the text in order to extract pieces of information necessary to answer specific test items (Urquhart \& Weir, 1998). Expeditious reading can be conducted at the local level (scanning) or at the global level (search reading and skimming).

Local expeditious reading (Scanning): In scanning which occurs at the local level, the reader, attempting to dismiss any part of the text that does not contain useful information for answering a specific test item, processes the text selectively in order to achieve specific goals (Weir \& Khalifa, 2008). According to Urquhart and Weir (1998), scanning involves reading a text quickly to find a specific symbol or group of symbols like a particular word, phrase, name, figure, or date. In this process, most of the text is ignored and its linearity is not observed. In Grellet's (1987) opinion, scanning is done at a higher speed than skimming and after finding the objective, the reading stops. 
Global expeditious reading (Search reading): In search reading which occurs at the global level, the reader processes the text in order to locate only text information necessary for answering specific test questions (Urquhart \& Weir, 1998).

Global expeditious reading (Skimming): In this type of reading, the reader processes the text in order to obtain the gist (Levine, Ferenz, \& Reves, 2000; Weir, 2005; Weir \& Khalifa, 2008). Grellet (1987) describes skimming as a quick reading of a text to get the central meaning of it, to understand how it is organized, or to obtain an idea of the tone or the intention of the writer. In addition, Urquhart and Weir (1998) listed operations which might be involved in skimming as identifying the source, reading titles and subtitles, reading the abstract, introductory and concluding paragraphs, the first and the last sentences of each paragraph, identifying discourse markers, skipping clusters of details, noting repeated key words, and looking at any non-verbal information.

Hughes (2003) on testing reading explained that any serious testing of expeditious reading will require candidates to obtain main ideas and discourse topic quickly and efficiently, establish the structure of a text quickly, and decide the relevance of a text (or part of a text) to their needs. He added in search reading the candidate can quickly find information on a predetermined topic. In scanning, the candidate can quickly find specific words or phrases, figures, percentages, specific items in an index, and specific names in a bibliography or a set of references.

Careful reading: It may take place at a local level of understanding lexis and identifying grammar or at a global level of seeking accurate comprehension of explicit meaning and making inference.

Careful reading at the local level: It is operationalized through identification of lexis, understanding syntax, seeking accurate comprehension of the explicit meaning (Khalifa \& Weir, 2009; Weir \& Khalifa, 2008).

Careful reading at the global level: It refers to different operations through which the reader attempts to extract complete meaning within or beyond sentences right up to the level of the entire text so as to construct the text macrostructure (Khalifa \& Weir, 2009; Weir \& Khalifa, 2008). In Urquhart and Weir's (1998) opinion, to identify explicitly stated information, the reader should decode the whole text. In other words, the text should be read from the beginning to the end in a linear and sequential fashion, returning to the previous parts only as required. On the other hand, making inferences is a creative process by which the reader relates his/her knowledge to what is stated in a text in order to make it coherent (Weir \& Khalifa, 2008).

\section{Careful reading comprehension at the levels of sentence, text, and multiple-text}

Careful reading comprehension at the sentence level (Sentential): Khalifa and Weir (2009) defined it as a bottom-up process, starting with linguistic processing of elements of a sentence and establishing propositional meaning (the literal interpretation of what is printed on the page).

Careful reading comprehension at the textual level (Textual): With regard to the reading comprehension at the level of a text, Khalifa and Weir (2009) stated that micro propositions integrate into macropropositions and the recognition of the hierarchical structure of a text is of crucial importance in forming a unified understanding at this level of reading comprehension.

Careful reading comprehension at the inter-textual level (Inter-textual): In Khalifa and Weir's (2009) reading framework, it was acknowledged that reading at the inter-textual level requires additional cognitive processes beyond what is required for understanding a single text-i.e., forming a global macro-structural organization in which selected information is combined and structured through higher semantic links. 
Hughes (2003) provided a list of twenty operations for careful reading as to identify pronominal references, identify discourse markers, interpret complex sentences, interpret topic sentences, outline logical organization of a text, outline the development of an argument, distinguish general statements from examples, identify explicitly stated main ideas, identify implicitly stated main ideas, recognize the writer's intention, recognize the attitudes and emotions of the writer, identify addressee or audience for a text, identify what kind of text is involved (e.g., editorial, diary, etc.), distinguish fact from opinion, distinguish hypothesis from fact , and distinguish fact from rumor or hearsay. In relation to making inferences, Hughes specified four types of inferences as "inferring the meaning of an unknown word from context, making propositional informational inferences, making propositional explanatory inferences, and making pragmatic inferences" (p. 139). Generally, making propositional inferences is based upon the information provided in the text, and making pragmatic inferences requires a combination of information from the text and knowledge from outside of the text. Further, in order to clarify what making inferences mean, Hughes listed inferring the meaning of an unknown word from context, making propositional informational inferences, answering questions beginning with who, when, what, making propositional explanatory inferences concerned with motivation, cause, consequence and enablement, answering questions beginning with why, and how, and making pragmatic inferences.

By taking the provided definitions cited in the literature, it can be concluded that careful reading at the local level involves processing a text until the basic meaning of a proposition is established whereas careful reading at the global level involves processing the text until its macro-structure is built.

\section{Conclusion}

The present study tried to introduce strategic reading as a holistic concept and endeavored to enlighten each aspect of it using reading models and frameworks presented in the related literature. In line with Dabiri et al. (2016) and Khalifa and Weir's (2009) reading framework, a cognitive processing approach as a theoretical framework was used as a base model in the present study. This reading framework is concerned with the mental processes readers actually use in comprehending texts when engaging in different types of real-life reading. In this approach, the cognitive, linguistic and contextual aspects of reading are unified into a more unified framework of reading. In the framework, the place and role of linguistic elements at different textual levels (global versus local) along with different reading skills and strategies (expeditious versus careful) were investigated and explicit references to contextual variables were made. The framework accounted for such important variables as the reader's purpose, comprehension focus, text coverage, rates of reading and relationship with the underlying processes. It combined premises of Kintsch and van Dijk (1978) and Just and Carpenter (1992) to adequately account for the reading behavior both at the local and global levels using expeditious and careful reading processes. The framework accommodated the cognitive processing required for different levels of reading starting from the word level and extending to the multiple text level. In the model, contextual parametersi.e., text and task features, performance conditions that affect reading comprehension and thus test performance-were explicitly accounted for.

\section{References}

Bensaad, S. \& Ghania, O. (2020). An examination of reading strategies awareness among Algerian ESP students at the National Higher School for hydraulics. Journal of Language and Linguistic Studies, 16 (4), 1784-1802. DOI: 10.17263/jlls.851001

Britt, M. A., \& Sommer, J. (2004). Facilitating textual integration with macro-structure focusing tasks. Reading Psychology, 25, 313-339.

Carrell, P.L. (1989). Metacognitive awareness and second language reading. Modern Language Journal, $73,121-133$. 
Carver, R. P. (1997). Reading for one second, one minute, or one year from the perspective of rauding theory. Scientific Studies of Reading, 1(1), 3-43.

Carver, R. P. (1998). Predicting reading level in grades 1 to 6 from listening level and decoding level: Testing theory relevant to the simple view of reading. Reading and Writing: An Interdisciplinary Journal, 10, 121- 154.

Coady, J. (1979). A psycholinguistic model of the ESL reader. In R. Mackay, B. Barkman, \& R. R. Jordan (Eds.), Reading in a second language (pp. 5-12). MA: Newbury House Publishers.

Cohen, A.D. (1998). Strategies in learning and using a second language. London: Longman.

Dabiri, A., Rashidi, N., Saadat, M., Sahragard, R., Alimorad, Z. (2016). Textual and intertextual analyses of Iranian EFL Undergraduates' Types of English Reading towards Developing a Careful Reading Framework Teaching English as a Second Language Quarterly (Formerly Journal of Teaching Language Skills), 34(4), 29-55. doi: 10.22099/jtls.2016.3657

Enright, M. K., Grabe, W., Koda, K., Mosenthal, P., Mulcahy-Ernt, P., \& Schedl, M. (2000). TOEFL 2000 Reading Framework. TOEFL Monograph Series, MS-17. ETS

Gernsbacher, M. A. (1990). Language comprehension as structure building. Hillsdale, New Jersey: Lawrence Erlbaum Associates.

Goldman, S. R., \& Rakestraw, J. A. (2000). Structural aspects of constructing meaning from text. In M. L. Kamil, P. B. Mosenthal, P. D. Pearson, \& R. Barr (Eds.), Handbook of reading research Vol. III (pp.311-335). Mahwah, New Jersey: Lawrence Erlbaum Associates, Publishers.

Grabe, W., \& Stoller, F.L. (2002). Teaching and Researching Reading. London: Longman.

Grellet, F. (1987). Developing reading skills. Cambridge: Cambridge University Press.

Hawkey, R. (2006). Impact theory and practice: Studies of the IELTS test and the Progetto Lingue 2000. Cambridge: Cambridge University Press.

Hughes, A. (2003). Testing for language teachers. Cambridge: Cambridge University Press.

Just, M. A., \& Carpenter, P. A. (1992). A capacity theory of comprehension: Individual differences in working memory. Psychological Review, 99(1), 122-149.

Khalifa, H., \& Weir, C. J. (2009). Examining reading: Research and practice in assessing second language reading. Cambridge: Cambridge University.

Kintsch, W., \& van Dijk, T. A. (1983). Toward a model of text comprehension and production. Psychological Review, 85(5), 363-394.

Krishnan, K. S. D. (2011). Careful versus expeditious reading: The case of the IELTS reading test. Academic Research International, 1(3), 26-35. Linderholm, T., \& van den Broek, P. (2002). The effects of reading purpose and working memory capacity on the processing of expository text. Journal of Educational Psychology, 94, 778-784.

Levine, A., Ferenz, O., \& Reves, T. (2000). EFL academic reading and modern technology: How can we turn our students into independent critical readers? TESL EJ, 4 (4), 75-91.

Meyer, B. J. F. (1999). Importance of text structure in everyday reading. In A. Ram, \& K. Moorman (Eds.), Understanding language understanding (pp. 227-252). Massachusetts: The MIT Press. 
Munby, J. (1978). Communicative syllabus design. Cambridge: Cambridge University Press.

Perfetti, C. A. (1991). Representations and awareness in the acquisition of reading competence. In L. Rieben, \& C. A. Perfetti (Eds.), Learning to read: Basic research and its implications (pp.33-44). Hillsdale, New Jersey: Lawrence Erlbaum Associates, Inc.

Perfetti, C. A. (1997). Sentences, individual differences and multiple texts: Three issues in text comprehension. Discourse Processes, 23, 337-355.

Perfetti, C. A., Rouet, J. F., \& Britt, M. A. (1999). Toward a theory of document representation. In H van Oostendorp, \& S. R. Goldman (Eds.), The construction of mental representations during reading (pp. 99-122). London: Lawrence Erlbaum Associates Publishers.

Poorbehzadi, A., Afraz, S., Samimi, F. (2020). Toward the Development of a Model of Teaching as Profession in the Iranian EFL Context: Insights from Iranian EFL Teachers. Iranian Journal of Applied Language Studies, 12(1), 217-246. doi: 10.22111/ijals.2020.5679

Rayner, K., \& Pollatsek, A. (1989). The psychology of reading. New Jersey: Prentice-Hall.

Rosenfeld, P., Oltman, P., \& Sheppard, K. (2004). Investigating the validity of TOEFL: A feasibility study using content and criterion-related strategies, TOEFL Research Report, RR-71.

Rumelhart, D. E., \& McClelland, J. 1. (1986). Parallel distributed processing: Explorations in the microstructure of cognition: Psychological and biological models. Cambridge, MA: MIT Press.

Stanovich, K. E. (2000). Progress in understanding reading. The Guilford Press: New York.

Urquhart, A. H., \& Weir, C. J. (1998). Reading in a second language: Process, product and practice. Harlow: Longman.

van Dijk, T. A., \& Kintsch, W. (1983). The notion of macrostructure. In T. A. van Dijk, \& W. Kintsch (Eds.), Strategies of discourse comprehension (pp.189-223). New York: Academic Press.

Weir, C. J. (1993). Understanding and developing language tests. Hamel Hewpstead: Prentice Hall.

Weir, C. J. (2005). Language testing and validation: An evidence-based approach. Palgrave: Macmillan.

Weir, C. J., Green, T., Hawkey, R., Devi, S., \& Unaldi, A. (2009). The relationship between the academic reading construct as measured by IELTS and the reading experiences of students in their first year of study at a British university, IELTS Research Report, 9, 97-156. British Council/IDP Australia.

Weir, C. J., Huizhong, Y., \& Yan, J. (2002). An empirical investigation of the componentiality of L2 reading in English for academic purposes. Cambridge: Cambridge University Press.

Weir, C.J., \& Khalifa, H. (2008). A cognitive processing approach towards defining reading comprehension, Cambridge ESOL: Research Notes, 31, 2-10.

\section{Copyrights}

Copyright for this article is retained by the author(s), with first publication rights granted to the journal.

This is an open-access article distributed under the terms and conditions of the Creative Commons Attribution license (http://creativecommons.org/licenses/by/4.0/). 